\title{
The Social Responsibility in the Formation of the Professional of the Communication and Its Professional Practice, the Case of a University of the Mexican Southeast
}

\author{
Gabriela Hidalgo Quinto ${ }^{1}$, Augusto Renato Pérez $\mathrm{Mayo}^{2}$, Jannet Rodríguez Ruíz ${ }^{1} \&$ Nohemí Roque Nieto ${ }^{3}$ \\ ${ }^{1}$ Research Professor, Juarez University Autonomous of Tabasco. Group Member of Research Organization, \\ Communication and Language, Mexico \\ ${ }^{2} \mathrm{PhD}$ Department of Studies of the organizations and Sociology of Organizations Faculty of Accounting, Management, \\ and Informatics, The Autonomous University of the State of Morelos, (Acronym UAEM), Mexico \\ ${ }^{3} \mathrm{PhD}$ Department of Studies of the organizations and Sociology of Organizations Faculty of Accounting, Management, \\ and Informatics, The Autonomous University of the State of Morelos, Mexico \\ Correspondence: Augusto Renato Pérez Mayo, PhD Department of Studies of the organizations and Sociology of \\ Organizations Faculty of Accounting, Management, and Informatics, The Autonomous University of the State of Morelos, \\ (Acronym UAEM), Mexico.
}

Received: June 1, 2020

doi:10.11114/ijsss.v8i5.4939
Accepted: July 1, $2020 \quad$ Available online: July 22, 2020

URL: https://doi.org/10.11114/ijsss.v8i5.4939

\begin{abstract}
The objective of this work is to analyze the Social Responsibility of graduates of the Communication Degree from the Universidad Juárez Autónoma de Tabasco, in the professional practice in the Tabasco companies. Through a comparative study, we will know the academic training versus the professional practice of those in charge of the organizational communication and if this meets the needs of the companies (interest group). It is important to consider that the SR is not focused on a particular aspect but involves social, economic and environmental actions among others, so the university has a social commitment to train professionals to meet the needs of the environment, and the communication professional It has an important role in publicizing the actions carried out by organizations in favor of their own publics. Thus, having a communication professional who handles information responsibly will allow us to create an adequate image before society in general. A qualitative study was conducted through semi-structured interviews with personnel working in the area of organizational communication, the sample was carried out through snowball. The results indicate that the formation of communication students corresponds to the needs of the organizations, however, they have had to look for ways of training to complement their practice, so it is necessary to look for strategies that allow to adapt the training of the students. students and better meet the needs of the professional field.
\end{abstract}

Keywords: social responsibility, organizational communication, professional practice, stakeholders

\section{Introduction}

\subsection{Importance of the Social Responsibilities and Communication in Organizations.}

The Social Responsibilities according with Cajiga (2009) is a way of management and negotiation in which, companies look for sustainable actions in an economic, social and environmental way, attending the necessities of interest groups in which it relates to, "Is a business vision that integrates respect for people, ethnic values, community and the environment with the management from company itself, independent from the products and services that it offers, the sector which it belongs to, or its size or nationality" (Cajiga Calderón, 2009, p. 2).

The universities must have as an objective to attend the necessities of their environment through the formation of their students, their plans and study programs must be designed to obtain the required knowledge that allows them to answer to social problematic, cultural, economics and policies of their environment. For the previous one is important to know if the professional practice from the institution graduates is attending such problematic.

The Higher Education Institution (IES) form Tabasco's southeast in which it references, has among its Educational 
Programs (PE) with the Communication Degree which arose in 1991 and had two curricular restructurings, the first one in 2007 and the second in 2010, in a way in which they adapt to the contents of the labor demand from the productive sector.

This investigation looks forward to analyze, starting from the context of the social responsibilities, the relation that exists between the academic formation of the Communication Degree, taking as reference the Study Plan 2010, and the functions that realizes in the organizational communication camp specifically, to know the social reality in which the graduates face.

The Study Plan 2010, still valid, has as objective to:

Form professional leaders in the communication camp form a interdisciplinary perspective, with an innovative vision and broad culture, to stat communicative strategies that allow to overcome problems and identify opportunity areas in different communication scopes, to improve the processes of information and interpersonal, organizational, institutional and social communication. (DAEA, 2012)

This program is divided in four formation areas: 1) General, 2) Professional Substantive, 3) Professional Integral Formation and 4) Transversal Formation; with eight disciplinary fields: General, Communication Fundaments, Language and Communication, Methodology, Emergent Communication, Organizational Communication, Publicity and Design and Divulgation.

The Communication Degree must count with specific knowledge about the organizational area that allows it to have the capacity of design, plan, elaborate, analyze, and criticize, among other fundamental abilities to exercise their profession in this labor field. The management or task of the organizational communicator is to ease the path to commercial successes and the organization services, such as improving the tracks inside the company seeing that each part connects in a appropriate way, making effective use of the communication media in their reach.

The organizational field allows for new gaps to be opened for the candidate and the graduate from the Communication Degree, so it must know the role that this professional has in the company. The organization is the only method in which the desired purposes are reached, just as peace, prosperity and social justice. (Etzioni, 1993, p.33) It's important for the companies to announce the actions they perform, through media and language that allows them to design and/or maintain a favorable image to their, so counting with a communication professional should be a way to achieve it. Despite a lot of organization don't recognize the importance of communication as a fundamental element for their development and growing yet, this is a field of opportunities for the communicator that allows to them put in practice the social responsibility.

Just like people, organizations can't survive in an isolated way, they are in constant relationship with their groups of interest, so in an implicit or explicit way, they are always communicating something through their actions, it's an interest for the companies to take awareness of the importance that communication has as an essential element for maintaining relations with its environment and act with social responsibility creating a favorable image to the society.

According to Orjuela (2011) "the RSE can't untie to communication, due to it being the key to achieve a synergy between the organization and their different stakeholders, in which it works, coexists and transforms" (p. 138) When the communication is applied to organization it's denominated organizational communication, this is given naturally in any organization, whichever their type or size is and in consequence it isn't possible to imagine an organization without communication. Under this perspective, Fernández (2012) defines the organizational communication as "a total set of messages that are exchanged between the members of an organization, and between itself and its media" (2012, p. 19).

There exists some works that stand out the relationship between social business responsibility and communication, Briceño, Mejías and Moreno (2010) remark the importance of communication as a transversal axis in an organization and a tool for management to support the divulgation of ethnical and responsible practices. These author affirm that "the organizational actors must involve in the communication for the strategic of the organization, developing successful strategies of good practices, in the search of appropriate answers and adequate to the requirements of society" (Briceño et al., 2010, p. 37).

In its part, Orjuela (2011) talks about communication as an RSE axis, allowing to organizations to take awareness to the importance of having an ethical behavior that fortifies the management of its identity through its values and manage their image and corporative reputation in a transparent and reliable way, through its groups of interest and achieving a tripartite benefit: company-society-State.

Solano (2015) focus his text Social Responsibility and Reputation in a Corporative Communication in the keys of communication that companies use to create a favorable image among their public, satisfying their necessities and interests, through socially responsible, attending the modern environment requirements, evolution and social progress. 
The evolution of RS allows us to understand when organizations must consider the need to count with communication professionals that can design strategic communication plans that involve intern and extern groups of interest of the company, in order to maintain a favorable image among these, likewise to allow to make correct use of the information and media to maintain them informed about socially responsible actions that are accomplished in benefit of the environment. Throughout this investigation we look for analyzing the social responsibility in the professional practice of the graduate from the Communication Degree of the Autonomous University of Juarez from Tabasco, in Tabasco's companies and to identify if thought these ones environment necessities are attended.

For the accomplishment of the previous statement we look for answering the next questions: Does the Communication Graduated answer to the local business need through his professional practice? We identify the organizational communication functions that graduates perform in the labor field and if this ones allow us to satisfy the need for the business and also for the social environment.

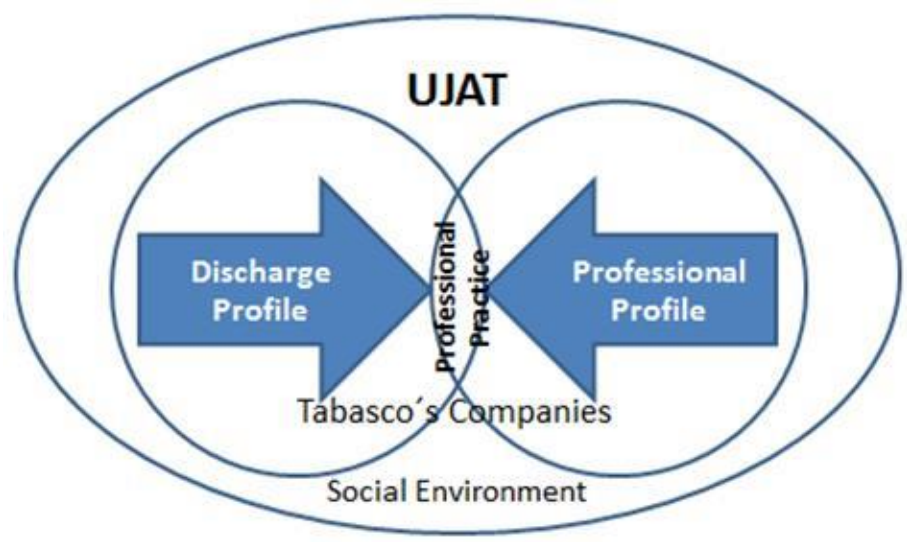

\section{Context of the Communication in Organizations}

The organizational communication is a fundamental part for the administrative tasks, the element that makes it possible for the union between all the business individuals and their exterior, the professional from this field works as an information administrator, this means, he must have knowledge of the messages that have to be transmitted to each ones of the public - interns and/or externs - choosing the right media for these and at the same time, waiting for an answer that the messages were sent properly.

Saladrigas Medina (2005) mentions that the organizational communication degree pretends, among other things:

creating an exterior image of the company, coherent with the corporative identity, that strengths their adequate positioning in the market and achieving a permanent adaptation to the changes of the environment through updated knowledge from the competence sector in a way that allows us to know in an exact way the possible necessities, desires and behaviors of their actual and potential users; the movements of their competitors and the rest of the environment factor that ease or blocks business activities, for the purpose of elaborating and deploying an adequate strategy that assures success.

Heydebrand (1989) in the other hand mentions that in the future there will be new organizational ways, new progress in communication channels and the processing of information would be the essence, the way it would be led. That time has come and it's important that a company reaches an internal balance to introduce a healthy image, competitive, capable of maintaining customers and suppliers interested, generating good relations with their.

Here enters again an organizational communicator, who's in charge of generating plans for the company for its internal growth, due for it being a successful company, it's important that there is an internal balance in every area. The organizational communicators are formed to qualify the employees of an organization; for being public relationships and making a company work managing every message in a correct way. The previous approach is urgent to every company and institution, the necessities that they have are now changing, because, it's important that the universities form organizational communication professionals capable of adapting to this constant change, with a knowledge of new focus and theories for the investigation, and abilities that allow them to manage with efficiency and effectiveness the processes of communication on organizations.

Sánchez (2004) talks about the importance of the organizational communicator work and the relationship with its environment, he explains the areas in which an organizational communicator develops inside a company, the importance 
that people have in this position, just like the responsibilities that their work carries, explains in detail the tasks in strategy planning and production for communication, the management of human resources, the preparation of policy manuals and entertainment procedures and programs in communication, it concludes that thanks to the cultural change in companies, this ones actually require very specified communicative backups.

Guerrero in the same way, purposes in his article "Role of the Communicator in Organizations" the importance of the professionals in the companies in a changing society, in which the technological advances are very notable and useful to the organizations, due to this a communicator must be careful to the things that are happening in his environment. He explains that the organizational communicator role has changes progressively, adjusting to the necessities of the companies, due to them needing to be capable to contribute to the cultural change of the company through the implementation of models that allow to modify the mentality in every level of the organization. This remarks the importance for the organizational communication professional works with all of the other organization areas, for the acceptance of any change inside of itself and concludes in this new era, it must be the correct person, creative, competent, effective and a leader, updating in all of the new tools that technology provides us to provide communicational strategies that allows it to connect between and the organization and their actors.

\section{Benefits of Communication with Social Responsibility}

The current investigation contains a descriptive-type study whit a quantitative focus. In this way, descriptive studies look to specify properties, characteristics and people's profiles, groups, communities, processes, objects or any other phenomenon that revolves an analysis, in quantitative studies their purpose is to measure in an independent way or to combine the variables that allow to prove the phenomenon study in particular and establish the relations (Hernández, 2014). What we need for this investigation is just to describe the dominant culture of an organization in Mexico. This information will allow us to determinate the aspects of its culture. The Organizational Culture Inventory was used (OCI; Cooke \& Lafferty, 1987) which is a quantitative instrument from Cooke y Lafferty. The design of this investigation can be defined as non-experimental. Non-experimental investigation is to observe phenomena the way as they are given in their natural context, to analyze them later (Hernández, 2014). The collection of data for this study was in a transversal form due to the collection of data being in a limited time. The sample to considerate for this study is from 73 employees of the Hotel, being a $100 \%$ of employees.

\section{Results}

The previous sketch shows us that social responsibility isn't a fashion, if not a series of actions that allows it to take organizational decisions for the benefit of the company, in a same way, the organizational communication is an actual proved necessity. The communication boom in organizations as a part of the business success is undisputed, little by little the directors have been realizing that the good functioning and achievement of objectives in a company, whatever their twist is, is based not only on quality of their product or service, if not also in the good functioning and adequate structure of their communication networks and maintaining of a good image among their public.

Due to this cultural change in companies, the graduates from Communication Degree must be professionally prepared to confront the change and innovation processes that allow them to attend the necessities of their environment. This study counts with the correct data to know the academic necessities that a student from the Communication Degree requires for his professional practice in the labor field. It shows the difference between a communication graduate during his academic formation and the reality he will face during his labor activity.

The investigation covers new tendencies in which the University can make value for an update in the study plan of the career, implementing new assignments specifically focused for the preparation of the organizational communicator as much as in theories and practices, giving as a result an innovation in the degree and contributing to the ideal training for the Communication Graduate to perform his tasks in the labor area in a professional manner.

The degree candidates and the ones actually coursing it, can obtain more knowledge about the organizational field, which counts with opportunity areas for their professional development in a company, giving to know the activities and strategies that an organizational communicator realizes inside a company, in a detailed way and explaining the benefits that their labor brings, besides breaking paradigms about the professional communication field.

We are looking to highlight the importance for the universities to comply with the social responsibility of forming professionals that answer their environment necessities, through the role of the organizational communicator, that businessman and/or organization directors to know that it is fundamental and indispensable for this professionals to contribute make the company grow through effective management of information and maintenance of the favorable image such as interior and exterior.

In the social aspect, it is shown to the companies the benefits of hiring an organizational communicator, knowing the profile and functions that can perform as an specialist from this area, to make their communication tracks stronger such 
as interns and externs, in this way the organization will look with more strength due to its good personal management, they'll obtain a good image, better leadership, a motivated and enthusiastic environment, good relationships with its customers and suppliers, among others. Without a doubt, an actual business necessity is to maintain their organization bonds strong and secure to an internal and external level, for that it requires of an organizational communication expert.

In this point, we can appreciate that not only talk about a social responsibility of the university in the formation of their professionals; we also make references to the importance of the communication as a transversal axis of the organizations to perform the social responsibility of itself. If we consider the last thing, we can appreciate that if one organization handles correctly their communication, it can maintain a positive image for the company, even to those groups that are not their customers.

Antezana (2011) mentions that the social responsibility is not just an action, if not also communication, this is because the companies must be ready to have a channel were the community can speak through-positive or negatively - and suggest the action fields that can benefit the society in which the organization is located "A bad communicational management can turn in to a boomerang that generates negative perceptions that are hard to erase"

\subsection{Egress Profile versus Professional Profile}

In the organizational study field, the investigation is qualitative; we took interviews with the graduates from the Communication Degree, that is working in the organizational field. The study is transversal due to it being realized in a determinate time. The analysis units were 13 graduates from the Communication Degree from the study plan 2010, that work in companies from the state of Tabasco. This was determined by snowballing because it allowed identifying potential study subjects through a chain, due to after investigating the first subject, this one helped to find another graduate to reach his limit.

We did use of the semi structured interview composed by six questions, the first three with multiple choices that allowed to identify the size of the company, the twist of itself and the area where the graduate is working on1. The next three questions looked to identify the existing relationship between the organizational field from the study plan 2010 and the professional practice the graduates realize in companies were they work on.

The answers to these questions were open to give them the chance of mentioning each of their assignments, topics and techniques that they took during their academic trajectory and previously have put in test in their labor. Throughout the first results the social responsibility analysis of the organizational field from the Communication Degree of the University of the Mexican Southeast is realized.

\subsection{Social Responsibility and Organizational Communication}

Talking about the organization size, these can be divided in small, medium and large. The first one, according to Fleitman (2000) have a growing rhythm normally superior to the micro company, there exist more job division because the number of employees is less than 25 ; there exist more complexity to the functions and difficulty for problem solution. This organization requires of an adequate function division, authority delegation and a mayor organization.

Medium companies on its part, have between 50 and 250 employees according to the same author aforesaid, they're dependent entities with a wide predominance in the market commerce staying practically excluded from the industrial market because of the big necessary investments and for the limitations that the legislation imposes depending the volume of staff and business.

Finally the large companies are those that create wealth and obtain bigger benefits. A large company is defined because it counts with more than 250 employees, this one provides more than the half of the jobs in one city and the job division is wide. From 13 graduate interviewed that work on companies from the state of Tabasco, 7 people are found working on large companies, 5 people on medium companies and 1 in a small organization. This means that most of them had situated themselves in companies with a balanced economy and the opportunity to grow in a professional manner.

The next question allowed us to know the twist of the organization. By twist me mean for the magnitude of a company conditioned to the activities that it dedicates to and the sector that leads their services, these can be public or private. In the interview 12 of the graduates answered that they are working in private companies and person in a public company. During the interview the mention that working in a company form the private sector gives better opportunities to ascend to other positions and as consequence to obtain a bigger salary. Private companies handle much more stability, because their directives, generally stay in large power periods. This is probable due to their permanency on the job not depending on the change of management, something that does happen with a few public employees, who are in risk of being removed of their charge when the sector boss changes. The subsequent question is referred to the area in which

1 The work areas were taken from Fleitman (2000). 
the graduates are found working, the options were the next:

1. Educative: People who work in this area are unwrapped in the scholar ambit that carries from preschool to university, and keep the function of creating educative programs that make a better teaching quality in the learning for students and teachers. In the medium superior level also can work as a vocational counselor in which can help the students to choose over their career or labor activity, to detect learning programs with the student and/or teacher and to offer new techniques for a better quality in education.

2. Social: It is called social communication area to the one that studies and investigates questions such as communication, information, expression, massive communication media role and cultural industries.

3. Administrative: This area depends from the correct making of management tools such as management reports, budgets, planning, also from the frequent reports elaborated for their presentation among thirds. They also deal with the modern focus of control to prevent conflicts and shelter the organization assets, making efficiency better in the performance boosting guidelines for auto control.

4. Human resources: The first labor of this area is to make staff planning, that is to say, to determine which is the necessity of workforce that the company will have in a determinate season, which type of profiles are going to be necessary, which type of contracts are going to be realized and what is going to be their cost. After planning comes the search, it goes through the staff selection phase. Once it's established which employee profile is going to look for the company, we begin to search for candidates giving publicity of the existent vacant. The more common way is to do it through specialized job portals on the web. Later to hire, forming the staff, managing payrolls and benefits and to evaluate continuously the already hired staff.

From the total interviewed, 8 people worked on the administrative of the company, 4 in human resources and one in the educative area. This translates in which most of the graduates achieved to get a position according to their formation in the organizational area, the advantages of working in this area allows them to keep reinforcing the learned knowledge during their academic trajectory and developing new abilities and knowledge that thanks to the experience during their job they obtain.

The next three questions look to identify the relationship that exists between the organizational field from the study plan 2010 and the professional practice that they realize, the answer were opened type, providing the opportunity of mentioning the assignments that they took and posteriorly how the knowledge generated by these were used in the practice of their labor, they also mentioned the abilities and competitions they acquired in the area they labored in, obtaining the next evidence that show on the table 1 .

The obtained results in the academic learning area and professional practice are congruent each other, the acquired knowledge in the organizational field are very important and useful in the profession exercise. On the previous table, the assignments that are shown are all the ones that are very important for developing professionally inside a company; the assignments with a considerable use among the graduates are organizational communication and organizational behavior, which they provide the tools, techniques and abilities to use frequently inside a company just like they showed.

The benefits of having an organizational communication professional in the work team will allow us to count with a mediator, a leader, he can generate a good interaction among its areas; motivate the employees to have a more efficient control and direction.

As to the public relationships, the graduates exercise it through the search of suppliers and clients for the organization in which they work on, sell publicity spaces inside of television channels and broadcasters and offer services and/or products of the company working the role of sales agents due to the utilizing the correct use of language and oral and written expression, one of the fundamental values in the graduate profile of communication in the study plan 2010.

The graduates find the corporative communication in the professional practice essential due to it being manually elaborated for the organization, they look to satisfy the needs of the public through a quality and professional service, they help the company to select staff, mainly for the people that work in the human resource area were they choose the next staff on detail and identify in them the abilities and aptitudes that they must have to be part of an institution.

The culture in the company is a permanent seal for the employees that work in it, meaning with culture for quality, the graduates know very well the importance of knowing the norms in a organization, they know the identity of the company and they make great value of the culture that this one provides them to make them part of it. The graduates know that they are part of this system and that their collaboration defines them in a concept of global. 
Table 1. Results Comparison

\begin{tabular}{|c|c|c|}
\hline Academic Learning & Professional Practice & Independent Learning \\
\hline Public Relationships & $\begin{array}{l}\text { Looking for suppliers } \\
\text { Selling publicity spaces } \\
\text { Offering Services }\end{array}$ & $\begin{array}{l}\text { Demonstrate confidence and security } \\
\text { How to sell } \\
\text { Elaborating expedients of payment of publicity }\end{array}$ \\
\hline $\begin{array}{l}\text { Organizational } \\
\text { Communication }\end{array}$ & $\begin{array}{ll}\text { - } & \text { Mediator } \\
\text { - } & \text { Communication Channels } \\
\text { - } & \text { Leadership } \\
\text { - } & \text { Lines of hierarchy } \\
& \text { anteraction and communication with } \\
\text { - } & \text { Delivery of productivity reports } \\
\end{array}$ & $\begin{array}{ll}\text { - } & \text { Use of different software } \\
\text { - } & \text { Constructive reviews } \\
\text { - } & \text { Creating payrolls } \\
\text { - } & \text { Social Network }\end{array}$ \\
\hline $\begin{array}{c}\text { Corporative } \\
\text { Communication }\end{array}$ & $\begin{array}{l}\text { - } \quad \text { Manual Elaborations } \\
\text { - } \quad \text { Business Organization } \\
\text { - } \quad \text { Secessities from the public } \\
\text { - } \quad \text { Creating staff } \\
\end{array}$ & $\begin{array}{l}\text { - } \text { Observing attitudes of future employees } \\
\text { - } \quad \text { Assertive Communication } \\
\text { - } \quad \text { Usservation of the Office Pack } \\
\text { - } \quad \text { Image designing } \\
\end{array}$ \\
\hline $\begin{array}{l}\text { Organizational } \\
\text { behavior }\end{array}$ & $\begin{array}{ll}\text { - } & \text { Staff capacitation } \\
\text { - } & \text { Motivate the employees } \\
\text { - } & \text { Company control } \\
\text { - } & \text { Incention } \\
\text { - } & \text { Promote teamwork } \\
\end{array}$ & $\begin{array}{ll} & \text { Correct use of oral language } \\
\text { - } & \text { Corporal expression } \\
\text { Service attitude }\end{array}$ \\
\hline Culture for quality & $\begin{array}{l}\text { - } \quad \text { Company identity } \\
\text { - Knowing the policies } \\
\text { Creating and making value of the } \\
\text { organizational culture }\end{array}$ & - $\quad$ Knowing of labor laws \\
\hline $\begin{array}{l}\text { Organizational } \\
\text { Diagnosis }\end{array}$ & $\begin{array}{l}\text { - } \quad \text { To diagnose the company performance } \\
\text { - Observing the staff } \\
\text { To diagnose the communication } \\
\text { processes }\end{array}$ & $\begin{array}{l}\text { - To observe each area } \\
\text { - Verifying the correct use of communication media } \\
\text { inside the company }\end{array}$ \\
\hline Event organization & - $\quad$ Activity planning for publicity & $\begin{array}{ll}\text { - } & \text { Design colorimetry } \\
\text { - } & \text { Publicity campaigns } \\
\end{array}$ \\
\hline
\end{tabular}

Source: self made

The organizational diagnosis in a company is responsible of evaluating the situation of itself, its conflicts and its potential. This one looks for generating efficiency in the organization through changes. Three interviewed put this in practice through staff observation, the performance analysis of the company and verifying the internal communication process in the company, a little crowded area, but it goes accompanied of other tasks from the organizational field, these are not realized frequently, but is a labor that gets worked overall with the organization manager.

The event organization subject was the one that shined the least among the interviewed, but this is useful for someone on the activity planning to advertise the company, this is based on following a series of points during the week or month that requires it for advertising a service or product through events inside of the organization, promotions or getting to know to other companies for what this campaign tries to sell.

In the independent learning paragraph we can appreciate the competitions and abilities that we have been acquiring through the experience and what the positioning demands for the graduates to work on. The main names were the social networks and the use of billing systems, they mention that they are new tools that the degree should start to implement due to them being considered basic in the actual times to work in an organizational area, just like creating oral and corporal expression workshops for talking to a more than 10 people public projecting security and confidence, so this can be utilized with mayor for the people who are sales agents, public relationshipists, the people in the human resources area that interview other people, to give talks, conferences, expose manuals for the organization, among others.

The obtained results from part of the University graduates make to know that the professional practice in which they actually unwraps belongs to every one of the degree profile points from the study plan 2010 . We can detect that the knowledge provided during the academic formation are still latent in the graduated and are put in practice daily to exercise their profession. The study plan fulfills with the objectives of forming graduates in communication prepared for labor reality in Tabasco.

We can remark the role of the organizational communicator in companies, to know deeply their activities and how 
important are them for an institution. Because taking care of every pillar of an organization will maintain its foundation strong to fulfill the tasks of every one of its objectives.

\section{Conclusion}

Having an adequate balance between the profile degree and the professional degree is very important, for that, it's vital for a study plan to be structured according to the necessities that the labor field requires in this days and to act with Social Responsibility at the time when the universities studies and programs are being designed.

The investigation provided the differences that are between a communication graduate during his academic formation and the reality he faces during his labor activity. The study contained data from which the university can make use of for the update of the study plan from the degree, implementing new assignments focused specifically for the preparation of the organizational communicator such as in theory and practices, giving as a result innovation in the degree, and contributing to the ideal communication degree training to perform his tasks in an organizational area in a professional way.

We accomplished the objective of identifying the organizational communication functions that graduates from the University perform in companies from Tabasco, such as knowing the capacity from these to realize organizational communication activities in the companies and to analyze the relationship between their academic formation with the activities they perform in the organizational field in companies, which puts in evidence the accomplishment of the Social Responsibility in the Educative Program, for satisfying the environment necessities.

The obtained results allowed us to compare the degree profile with the professional profile from the graduates generating new data and tendencies that are now converted in necessities for the academic formation of future generations, due to the context and public necessities are always changing, it's necessary to fit the Educative Program to keep answering to these.

We could detect the organizational communication functions that the graduates from companies of Tabasco perform and also provided another type of abilities that acquired during their labor practice. The graduates from the communication degree are effectively trained to perform organizational communication activities inside the companies, in the obtained results we could observe that the knowledge and abilities generated during their academic trajectory are put to test and keep being very useful to exercise their labor.

The contrast between these two profiles demonstrate the importance of an organizational communication in companies, there exists a considerable demand for obtaining jobs in this field such as in small companies and big ones, it doesn't matter the twist you have in the institution.

Unfortunately we couldn't find more graduates that belong to the actual study plan and labor in the organizational field, but this group allowed us to have a wide perspective about the activities that are performed in the organizations and the need to start to implement new competences inside the study plan in the organizational area for the degree.

In a way of reflection, we can observe that there exists a coherency between the Study Plan form the degree from the University and the actions the graduates realize in the labor field of the environment, it is been acting with Social Responsibility, forming professionals that attend the context necessities of the companies, such as interior or exterior, and maintaining a favorable image for both publics and still who aren't public yet, but in deferent ways can impact them.

This exercise can help to make other fields stronger and to star investigating more deeply in every one of them and make a better study plan in general, allowing for the Communication Degree of the University from the Mexican southeast to continue being the best option for future generations.

\section{References}

Antezana, C. M. (2011). Responsabilidad social en comunicación. Recuperado el 19 de octubre de 2019, de Conexiónesan.

https://www.esan.edu.pe/conexion/actualidad/2011/11/29/la-importancia-de-la-responsabilidad-social-corporativa/

Briceño, S., Mejías, I., \& Moreno, F. (2010). La Comunicación Corporativa y la Responsabilidad Social Empresarial (RSE). Revista Daena (International Journal of Good Conscience), 5(1), 37-46.

Cajiga Calderón, J. F. (2009). El concepto de responsabilidad social empresarial. México: Centro Mexicano de Filantropía de México, 35.

DAEA, D. A. de E. y A. (2012). Guía Básica Plan de Estudios Licenciatura en Comunicación. Universidad Juárez Autónoma de Tabasco.

Fernández Collado, C. (2012). La comunicación en las organizaciones. 
Fleitman, J. (2000). Negocios exitosos: Como empezar administrar y operar eficientemente un negocio. McGraw-Hill.

Heydebrand, W. V. (1989). Nuevas Formas Organizacionales. Work and Occupations, 16(3), 356-377. https://doi.org/10.1177/0730888489016003004

Orjuela Córdoba, S. (2011). La Comunicación en la gestión de la Responsabilidad Social Empresarial. Correspondencias \& análisis, 1, 137-156. https://doi.org/10.24265/cian.2011.n1.09

Saladrigas Medina, H. (2005). Comunicación organizacional: Matrices teóricas y enfoques comunicativos. Revista Latina de comunicación social, 8(60), 1-7.

Sánchez Torres, C. A. (2004). El acto administrativo. Teoría general. Legis Editores SA.

Santos Solano, L. F. (2015). Responsabilidad social y reputación en la comunicación corporativa. Recuperado de https://dialnet.unirioja.es/servlet/articulo?codigo $=5753848$

\section{Copyrights}

Copyright for this article is retained by the author(s), with first publication rights granted to the journal.

This is an open-access article distributed under the terms and conditions of the Creative Commons Attribution license which permits unrestricted use, distribution, and reproduction in any medium, provided the original work is properly cited. 